\title{
Anotaciones críticas sobre las cegueras educativas: Los desafíos de una educación de calidad en la era conceptual
}

Critical annotations on educational blindness: The challenges of quality education in the conceptual era

\begin{abstract}
RESUMEN
El autor reflexiona con aproximaciones críticas sobre los principales desafíos de la calidad educativa en la era conceptual, el argumento principal es la necesaria correlación entre lo global y lo local, asi como el rol de los líderes de procesos educativos en evidenciar este panorama, que logre edificar una educación pertinente y transformacional así como propiciar procesos efectivos de gestión del conocimiento en el marco de las rendiciones de cuentas, que en últimas son los espacios que posibilitan los procesos de acreditación internacional.
\end{abstract}

\section{PALABRAS CLAVE}

Glocal, Era conceptual, Gestión del conocimiento, Rendición de cuentas, Acreditación internacional.

\begin{abstract}
The author reflects with critical approaches on the main challenges of education in the conceptual era, the main argument is the necessary correlation between the global and the local, as well as the role of the leaders of educational processes in highlighting this panorama, that manages to build A relevant and transformational education as well as fostering effective processes of knowledge management within the framework of accountability, which are ultimately the spaces that enable the processes of international accreditation.
\end{abstract}

\section{KEYWORDS}

Glocal, Conceptual era, Knowledge management, Accountability, International accreditation.

\section{EDIMER LATORRE IGLESIAS}

Doctor en Sociología Jurídica e Instituciones Políticas de la Facultad de Derecho de la Universidad Externado de Colombia. Sociólogo de la Universidad de Antioquia. Actualmente es Docente y Director del Grupo de Investigación de la Escuela de Derecho de la Universidad Sergio Arboleda Seccional Santa Marta. edimer.latorre@usa.edu.co 
INTRODUCCIÓN: LAS CEGUERAS EN LA Una nueva mente (A Whole New Mind), heGESTIÓN DEL CONOCIMIENTO

Cuando el cerebro sufre un daño en la región donde se procesa la visión, se produce el fenómeno denominado ceguera cortical, que no es más que una manifestación del daño ocasionado en la corteza occipital. Lo grave de esta enfermedad es que el ojo funciona de forma perfecta y esto da la sensación de que la visión es correcta, lo que genera en el enfermo la negación, es decir, él considera que aún sigue viendo. A este mecanismo de negación psicológica de la realidad, se le denomina síndrome de Antón (en honor al médico descubridor). Increíblemente los que padecen esta enfermedad simulan ver, aunque su cerebro no procese la información que transmite el ojo. De igual forma, muchos directivos de instituciones educativas se niegan a ver lo que hay en su entorno: la necesidad del cambio en una era de cambios.

La influencia de los altos directivos y de las personas que conforman una organización se hace notar cuando a través de un equipo de trabajo de alto desempeño, estos logran romper un proceso y redefinir una situación trastocando el orden de las cosas, rompiendo paradigmas y proponiendo nuevas formas que impliquen excelencia. En esta era de cambios, solo sobreviven las organizaciones que ven lo que otros no logran ver. Cuando me refiero a redefinir, me refiero a generar disrupciones en un trabajo, proceso, producto o servicio. mos pasado de la era agrícola a la industrial en este momento nos encontramos en la er conceptual, donde el activo fundamental es la creatividad y donde nuestra forma de pensar y re-pensar lo ya pensado, se convierte en un factor de alta competitividad. En la era conceptual los trabajadores se ven obligados a pasar al lado derecho del cerebro humano.

Los factores tales como la comunicación, la empatía, la creatividad, el trabajo en equipo y por supuesto el liderazgo, así como la capacidad de crear conexiones significativas con otros seres se convierten en las acciones determinantes del mundo organizacional. No basta con hacer productos, hoy por hoy, lo intangible es mucho más valioso que lo tangible.

Las instituciones educativas como sistemas organizacionales se ven en la tarea de crear significados colectivos con sus acciones, de dar un sentido a las áreas misionales y de generar una alta empatía. Pero para poder vivir en la era conceptual, la alta dirección de las instituciones educativas, debe saber manejar los conceptos claves que conforman esta definición, así como propiciar una cultura organizacional que privilegie y dinamice estas habilidades. De lo contrario las organizaciones educativas que no se adapten a las transformaciones que exige el entorno, sucumbirán impávidos ante los tsunamis del cambio irrefrenable.

De ahí la pertinencia de este artículo de rePara Daniel Pink (2008) en su exitoso libro flexión. Particularmente, el escrito gira en torno a la idea de hacer un planteamiento sobre los nuevos retos de la educación en esta dimensión holística denominada glo-cal; de igual forma se pretende señalar la importancia de la acreditación institucional en el marco de los procesos de la gestión del conocimiento y de la evaluación como retroalimentación

En el primer aparte se aborda el tema de la relación entre lo global y lo local, luego, en el segundo aparte se plantea la dinámica histórica del concepto de calidad y la importancia de su evaluación como retroalimentación de procesos de gestión del conocimiento, enmarcados en el contexto conceptual de la rendición de cuentas, elementos claves dentro de una acreditación internacional. En la tercera parte, se aborda la importancia de la acreditación internacional y se finaliza con unas conclusiones donde se explicita el rol del par internacional y su carácter deóntico. Todo ello en el marco reflexivo de la importancia de dejar de creer que vemos, cuando en verdad estamos ciegos.

\section{Educación en la era de la incertidumbre:} las exigencias del mundo global

El contexto global exige que la educación sea un modelo flexible, dinámico, incluyente y pertinente, propiciador de significaciones que transformen el entorno personal de mundo simbólico de la vida del sujeto activo y el entorno que rodea la vida activa del sujeto pensante. Es decir, se necesita urgentemente una educación que se conecte con e mundo de la vida para generar nuevas reali- dades desde lo propositivo argumental, capaz de trascender las turbulencias e incertidumbres que plantea el futuro más cercano.

Sobre la necesidad de replantear nuestro entorno educativo actual, las afirmaciones de Federico Mayor, que hoy adquieren alta relevancia, delimitan su ámbito, al redefinir el nuevo papel de la educación (Morin, 1999, p.6):

Cuando miramos hacia el futuro, vemos numerosas incertidumbres sobre lo que será el mundo de nuestros hijos, de nuestros nietos y de los hijos de nuestros nietos. Pero al menos, de algo podemos estar seguros: si queremos que la Tierra pueda satisfacer las necesidades de los seres humanos que la habitan, entonces la sociedad humana deberá transformarse. Así, el mundo de mañana deberá ser fundamentalmente diferente del que conocemos hoy, en el crepúsculo del siglo XX y del milenio. Debemos, por consiguiente, trabajar para construir un "futuro viable". La democracia, la equidad y la justicia social, la paz y la armonía con nuestro entorno natural deben ser las palabras claves de este mundo en devenir. Debemos asegurarnos que la noción de "durabilidad" sea la base de nuestra manera de vivir, de dirigir nuestras naciones y nuestras comunidades y de interactuar a escala global.

En este sentido, la época actual enfrenta como nunca la responsabilidad de redimensionar los procesos educativos $y$ de armonizar la forma como las personas aprenden a 
aprender. A pesar de las grandes exigencias de la globalización y de la necesidad de desaprender y re-aprender en entornos de in certidumbre permanente, la forma como se educa en Colombia en su gran generalidad, sigue atrincherada en la segunda ola, es decir, en la ola fabril de acuerdo a lo señalado por Toffler y Toffler (2006, p.277):

La mayoría de los empresarios y economistas convendrían en que si se mejora la educación de la fuerza de trabajo, probablemente se incremente la productividad de la misma. Sin embargo, como hemos visto, no hay ninguna institución supuestamente moderna más disfuncional y obsoleta que la que pasa por la educación pública, incluso en países de economía avanzada.

La obsolescencia de la educación estriba en un conjunto de factores que la hacen paulatinamente inviable y desfasada con relación al mundo veloz en el que nos hallamos coimplicados. Mientras el mundo del trabajo se reinventa constantemente a sí mismo, la escuela se encuentra formando e instruyendo para un mundo que ya dejó de existir. La rapidez y polivalencia de esta sociedad giran en torno a un combustible que la dinamiza: el conocimiento. De ahí que afirmemos que vivimos en una nueva sociedad, la sociedad del conocimiento, concepto que según Riesco González (2006, p.14):

Deriva de otro más restringido, la economía del conocimiento. Este último tuvo su origen en el ámbito de los negocios y se aplicó en las empresas que basaban su competitividad en los activos intangibles o capital intelectual. Cuando, por analogía e inferencia, se designa también a la sociedad en general, debería entenderse que esta se basa fundamentalmente en el conocimiento.

Lo anterior presupone que las nuevas tendencias educativas a nivel global involucren un cambio en las concepciones tradicionales que las Tecnologías de la Información y la Comunicación se conviertan en una herra mienta para poder aprender, des-aprenderre-aprender. El mundo de la segunda ola da paso al mundo de la tercera ola, o mejor aún da un paso hacia la sociedad en red (era de la información), donde todos los procesos se alimentan de la inteligencia colectiva, ta y como lo había planteado Manuel Castells cuando mencionó los factores constitutivos de una sociedad que gira en torno a la participación activa de los ciudadanos en la producción cultural de los medios de comunicación de masas:

los ciudadanos de la era de la informa ción son capaces de inventar nuevos programas para sus vidas con los materiales de sus sufrimientos, miedos, sueños y esperanzas. Construyen sus proyectos compartiendo su experiencia. Subvierten las prácticas de la comunicación tradicion ocupando el medio y creando el mensaje. Superan la impotencia de su solitaria desesperación interconectando sus deseos. Luchan contra los poderes establecidos identificando las redes establecidas.
Por eso la teoría -necesariamente fundada en la observación- es relevante para práctica: si no conocemos las formas de poder en la sociedad en red, no podremos neutralizar el ejercicio injusto de dicho poder; y si no sabemos exactamente quiénes tienen el poder y dónde encontrarlos, no podremos desafiar su oculta pero decisiva dominación. (Castells, 2010, p.552)

En este orden de ideas, la educación tradicional debe moverse en nuevas direcciones y una de ellas es la de la acreditación internacional. Es necesario y urgente relacionar los procesos educativos con los estándares internacionales de acreditación ya que estos propiciarían en las instituciones educativas locales, una inserción en el ámbito de lo global. Se estaría cumpliendo con uno de los presupuestos básicos de la globalización: lo glo-cal.

De ahí que sea necesario revisar los sistemas de gestión del conocimiento, dado que paradójicamente las escuelas, centros de educación y universidades deben convertirse en empresas que aprenden (Senge, 2002). En este sentido, la acreditación internacional, dinamiza la innovación, aporta al desarrollo y pone en contacto el mundo de las teorías con el mundo de lo real.

Veamos los ejes sobre los cuales se debe validar un proceso de acreditación internacional y por ende justificar la importancia del mismo dentro de las instituciones de educación superior.
2. Tres momentos históricos del concepto de calidad

Este contexto global obliga a repensar lo que entendemos por calidad. Es bastante difícil señalar con precisión qué es calidad, en particular cuando se quiere abordar el tema de la calidad de la educación superior. De ahí la importancia de precisar los cambios del concepto de calidad y de señalar las tendencias actuales en cuanto a la evolución misma del concepto en la era actual. Por ello se inicia con un recorrido de este concepto y particularmente a sus tendencias contemporáneas.

La calidad inicia en la era fordista (momento uno), por el método propuesto por la Ford que consistía en la cadena en serie o la cadena de montaje. A pesar de esto la lucha por realizar procesos de forma altamente efectiva era uno de los principales objetivos de este sistema. Sin duda, el primero en señalar la importancia de la calidad como presupuesto básico de competitividad fue William Edwards Deming. Desconocido en Norteamérica y altamente valorado en Japón, los principios de six sigma, se convirtieron en la esencia de la calidad a nivel global. Estos postulados son la base del pensamiento que mejora la cadena de montaje y las organizaciones piramidales.

Con una forma muy simplificada, el six sigma se posiciona y da inicio a los grandes procesos de aseguramiento de la calidad. Como su nombre lo indica, la calidad se ve desde la óptica del aseguramiento de procesos y de verificación de las no conformidades, para 
generar una mejora continua. Esta dimensión también se conoce como el improvement, es decir, los tomadores de decisiones deben revisar permanentemente los procesos para realizarlos ajustes necesarios.

Este modelo industrial entra en crisis, cuando colapsa la visión de la empresa nodriza y el marco que le daba sustento que es el Estado benefactor (Drucker y Maciariello, 2006). En medio de una crisis generalizada, aparece un segundo momento de la calidad: el toyotismo. Esta empresa japonesa, da un giro copernicano, al cambiar el proceso, que es absolutamente cerrado y racionalizante, a centrarse en el cliente, en la comprensión del mismo y en la necesidad de satisfacer plenamente sus necesidades. La empresa Toyota, simboliza esta segunda era del concepto de calidad. No bastaba con satisfacer las necesidades del cliente; en esta segunda fase, lo primordial es desbordar las expectativas de mismo. En este aparte la calidad se centra en los sistemas comunicacionales entre cliente y empresa (Liker, 2010).

Pero de esta visión centrada en el cliente, damos paso a una visión mucho más amplia del concepto de calidad, a la cual denominaremos Googlismo, de la empresa Google, ya que esta simboliza el futuro de las organizaciones, y se centra más en entender la calidad como el impacto que generamos en nuestros stakeholders. Esta concepción de calidad es más una visión de rendición de cuentas, de accountability, de conectarnos responsablemente con todos los que conforman y nutren a la organización (Schmidt y Rosemberg, 2015).
Hoy por hoy, las instituciones educativas se encuentran en una de estas eras, o están en el improvement o están en el accountability, pero muy pocas están centradas en su impacto con el entorno donde se desenvuelven. Lo explican taxativamente Gálvez y Haug (2006, pp.87-88):

Puede decirse, por tanto, que el propósito inicial de la evaluación de las Instituciones de Educación Superior estaba basado en la idea de accountability, de rendir cuentas a la sociedad o, lo que es lo mismo demostrar la eficacia pedagógica y académica de las instituciones universitarias, su eficiencia en términos del buen uso de los recursos y su pertinencia en lo que respecta a factores, efectos e impactos comuntarios, sociales y culturales. Posteriormente, empezaron a realizarse evaluaciones basadas en una perspectiva diferente, del improvement, es decir, lograr la mejora de la institución educativa mediante conocimiento de las cuestiones relevantes para la toma de decisiones.

Lastimosamente, en las instituciones educativas colombianas se entiende más el proceso de calidad como la revisión permanente de procesos en busca de las famosas no conformidades, lo que termina siendo un desgaste desde la perspectiva organizacional, ya que se destinan ingentes recursos $y$ talento humano a la perfección de los procesos, mas no a la revisión de cómo se está impactando efectivamente el entorno. Las universidades en Colombia obligatoriamente deben estar conectándose positivamente con el entorno, pero se mantienen obsesiva y ritualmente revisando sus procesos, los que las hacen olvidarse de sus stakeholders y de sus responsabilidades.

Adicional a esto, la evidencia de procesos en formatos de papel no certifica una calidad dado que muchos de estos, posiblemente no terminan más que siendo procesos que solo existen en el papel. De ahí el urgente e inaplazable imperativo de centrarnos en una cade la educación pensada sobre la rendición de cuentas. Es aquí donde la acreditación internacional juega un rol fundamental al y como lo señala el CNA (2015) desde un visión de rendición de cuentas y desde una visión del deber ser global:

En este contexto, los Sistemas Nacionale de Acreditación no tienen otra opción que la de internacionalizarse ellos mismos en el cumplimiento de sus funciones. Tradicionalmente el aseguramiento y fomento de la calidady bido como una función que se desempeña a interior de Sistemas de Educación Superior, limitándose a la acreditación de programas dentro de espacios nacionales. $\mathrm{Si}$ bien la acreditación nacional seguirá siendo la unidad básica de todo proceso de acreditación, y el Estado-Nación seguirá siendo el principal actor de dicho proceso, los Sistemas de Acreditación tienen que desarrollar una capacidad para operar e el ámbito internacional en el cumplimiento de sus funciones básicas, por varias razones. En primer lugar, las Agencias Nacionales de Acreditación están confrontando la creciente necesidad de "acreditarse" ellas mismas a nivel internacional, por medio de diversos mecanismos relacionados con la "evaluación externa internacional" de este tipo de agencias. En segundo lugar, las "decisiones de acreditación" que ellas toman deben tener una validez o aceptación internacional, ya que los mercados profesionales y las redes científicas en las que se insertan los egresados de los programas acreditados, crecientemente operan en la dimensión transnacional. Para lograr lo anterior, se están desarrollando sistemas internacionales (regionales o inter-regionales) de reconocimiento mutuo de los sistemas y agencias nacionales de acreditación, como un primer paso en la dirección del reconocimiento mutuo y la homologación de títulos académicos. Esto se está convirtiendo en una característica esencial de los Sistemas de Educación Superior del mundo globalizado del siglo XXI.

Veamos a continuación cuál es la esencia de un proceso de acreditación internacional.

\section{De la evaluación a la acreditación inter-} nacional: Un cambio en la búsqueda de la excelencia

Como se ha venido señalando, la globalización genera una serie de complejidades que es necesario pensar y re-pensar. La necesidad de homologar títulos profesionales, o al menos la necesidad de articular carreras académicas con posgrados, maestrías y doctorados a nivel global, hace esencial analizar los procesos de estandarización y por ende 
las formas como se pueden unir las univer- social o proyección social y Docencia o los sidades locales a nivel transnacional en pos procesos mediante los cuales se imparte la

de la excelencia. Se presentan las siguientes formación educativa. No se trata de medir problemáticas:

- Estudiantes de intercambio

- Profesores de intercambio

- Continuación de carrera y doble titulación

- Articulación de programas y de continuación de estudios

- Homologación de asignaturas

- Movilidad estudiantil

- Movilidad docente

- Investigaciones conjuntas con réplicas

- Estudios comparados de realidades.

Estas complejidades hacen que los procesos de acreditación sean prácticamente obligatorios a una escala supranacional. Como su nombre lo indica, la acreditación es el proceso mediante el cual se le reconoce a alguien que posee lo que dice tener en su autoinventario. Acreditar es darle solidez a una opinión, es la capacidad para afirmar legítima y legalmente que alguien es, quien dice ser. De ahí que la acreditación gire en torno a una verificación de condiciones de calidad educativa por parte de un agente externo, quien mediante el análisis entre pares (entre iguales), es capaz de decirnos si nos acercamos o no a los estándares de calidad previamente establecidos.

Casi siempre los procesos de acreditación internacional miden el impacto de la institución educativa en su entorno y la forma como este impacto recoge todos los elementos de proceso educativo: Investigación, extensión cuantitativamente, ni mucho menos medir únicamente desde la subjetividad; se trata de ser un evaluador, asumiendo la posición

de un juez. En este sentido, es preguntarnos cómo podría evaluar mejor, y qué se puede hacer para que podamos cumplir con el contexto social, brindando una educación de pertinencia y de impacto social que posibilite mejorar al conjunto social.

Tal vez una frase latina resuma esta idea: per aspera ad astra, que significa de la tierra a las estrellas, o desde las asperezas al cielo estrellado. Es en la dificultad donde se moldea la excelencia. Por ello un proceso de acreditación internacional está encaminado a revisar cuáles son las formas y mecanismos para alcanzar la excelencia, ese elemento que se convierte en un patrón diferenciador en la mediocridad de algunos de los sistemas educativos actuales.

Otro elemento que le da realce a la acreditación internacional, es la presencia de la mirada internacional. La gestión del conocimiento tiene un concepto que señala esta prácconoce como la práctica de imitación creativa. De ahí que someterse a una acreditación internacional posiciona el benchmarking, y que nos permite comparar, trasladar, ajustar e implementar. No es simplemente imitar como su nombre lo indica, es comparar y comodar, pero adaptando a las realidades locales y ajustando a las prácticas reales de tica: el benchmarking (Spendolini, 1992). Se la institución educativa. Se trata de mirar qué hacen otras universidades y preguntarnos ¿isi funcionó allá, qué necesitamos hacer para que funcione acá? Ese debate se propicia en el marco de un proceso de acreditación internacional.

Los japoneses tiene un lema que complementa este recorrido: Busque al mejor, aprenda del mejor, e imite al mejor, pero sobre todo, esfuércese para superar al mejor. Un proceso de acreditación internacional abre la posibilidad de conocernos, de ampliar nuestra mentalidad y de aprender como organización. No podemos vivir en la era del conocimiento sin aprender.

A MANERA DE CONCLUSIÓN: AMPLIAR A GEOGRAFÍA MENTAL

Para finalizar este trabajo es bueno caracterizar el rol del par, que agencia procesos de acreditación internacional. Esta persona debe ser un profesional altamente competente en las áreas del saber evaluar, pero debe tener cuatro características que lo hacen ser competente y competitivo, llamémosle los cuatro pilares. El primero de ellos es que debe tener una geografía menta amplia. Por esto no se debe entender, simpemente los conocimientos geográficos que osea, sino su capacidad para entender e mundo y su relación con lo glo-cal. Este concepto fue acuñado por Peter Drucker (2006) y señala cómo las personas son capaces de ven una conexión entre lo local y lo glo-
Además de la visión de lo global, un buen par internacional, debe estar dispuesto a evaluar. Este segundo pilar, no es solamente cuestionar que las cosas no se hagan como uno quisiera que se hicieran, sino todo lo contrario, analizar cómo se hacen y qué se puede aprender, y cómo se pueden sugerir aprendizajes significativos, para que determinado proceso funcione de la mejor manera.

El tercer pilar nos lleva a adentrarnos en la esencia de un par que acredita a nivel global, y es precisamente la rendición de cuentas. Un par debe tener la capacidad de preguntarse por los impactos y avances de una universidad en su entorno, por la función social de una universidad o por sus logros en una determinada comunidad. Esto significa evaluar con sentido social.

Y la última característica es ser un juez. Evaluar con los dos hemisferios: el derecho y el izquierdo, es decir, conjugar razón y emoción, posibilitar el encuentro mítico-mágico entre lo que se piensa y lo que se siente. Obviamente las afirmaciones del juez deben generar la desestabilización, deben potenciar una capacidad de transformar, re-definir y sobre todo trastocar el orden de las cosas, esto enmarcado en las ideas de Drucker que nos sirven de colofón a este trabajo:

La sociedad, la comunidad y la familia son, todas, instituciones conservadoras. Tratan de mantener la estabilidad y evitar el cambio o, por lo menos, demorarlo. $Y$, sin embargo, también sabemos que las teorías, valores y todos los dispositivos de la 
mente humana envejecen y se fosilizan, se vuelven obsoletos, se convierten en aflicciones. ...La única manera como una institución -sea entidad de gobierno, universidad, negocio, sindicato, ejército- puede mantener continuidad es involucrando una innovación sistemática en su propia estructura. ...La organización moderna tiene que ser desestabilizadora, tiene que estar organizada para la innovación. (Drucker, 2006, p.49)

REFERENCIAS BIBLIOGRÁFICAS

Castells, M. (2010). Comunicación y Poder. Madrid: Alianza Editorial.

CNA (2015). Consejo Nacional de Acreditación. En: http://www.cna.gov.co/1741/articles-186353_recurso_1.pdf

Drucker, P. \& Maciariello, J.A. (2006). Drucker para todos los días: 366 días de reflexiones clave para acertar en sus negocios. Ediciones Granica, S.A.

Egido Gálvez, I. \& Haug, G. (2006). La acreditación como mecanismo de garantía de la calidad: tendencias en el espacio europeo de educación superior. Revista Española de educación comparada, 12.
Liker, J. (2010). Las claves del éxito de Toyota: 14 principios de gestión del fabricante más grande del mundo. Barcelona: Planeta.

Morin, E. (1999). Los siete saberes necesarios para la educación del futuro. UNESCO.

Pink, D. (2008). Una nueva mente: una formula infalible para triunfar en el mundo que se avecina. España: Ilustrae.

Riesco González, M. (2006). El negocio es el conocimiento. Argentina: Ediciones Díaz de Santos.

Schmidt, E. \& Rosemberg, J. (2015). Cómo trabaja Google. Barcelona: Aguilar.

Senge, P. (2002). Escuelas que aprenden. Bogotá: Grupo Editorial Norma.

Spendolini, M. (1992). Benchmarking. Bogotá: Grupo Editorial Norma.

Toffler, A. \& Toffler, H. (2006). La revolución de la riqueza. Bogotá: Editorial Debate.

\section{Derecho del Consumo en Colombia: Acerca de la construcción de un marco histórico y conceptual $^{*}$}

Consuption Law in Colombia: About the construction of a historical and conceptual framework

\begin{abstract}
RESUMEN
posible remión contractual tiene su origen en el Derecho romano desde una perspectiva civil. Sin embargo es normativas propias a favor de los derechos de la parte débil en las relaciones contractuales. En Colombia esta rama del Derecho Comercial es reciente, puesto que de hecho fue solo a partir de los años 80 que se expidió
un Estatuto del Consumidor, y por demás, solo alcanzó raigambre constitucional con la Carta Política de 1991 protegiéndose a los consumidores, en su calidad de destinatarios finales de los bienes y servicios en la relación de consumo, a traves de la intervención y dirección del Estado y el reconocimiento de los derechos de los consumidores como derechos colectivos. Este trabajo plantea el desarrollo histórico y juridico del derecho del
consumidor en el contexto colombiano, teniendo como eje articulador la constitucionalización de dicho derecho a partir de la Carta de 1991.

PALABRAS CLAVE

, Consumidor, Constitucionalización, Derechos colectivos.

ABSTRACT

Us to consual protection has its from a private law perspective origins in roman law. However, it is possible to refer which tender to favor the watonomous branch since the second half from the XX century, with own regulations considerably new, because, in fact, it wast just from the $80^{\prime}$ 's, that was issued a Consumers statute, and it jus final receivers of goods and services in the consumer relationship, through the intervention and direction of the Estate and recognition of consumers rights as colectives rights. This work presents the historical and legal of consumers law in the colombian aspect, having as articulator axis the constitutionalization of that law from the
\end{abstract}

KEYWORDS
Consumer law, Consumer, Constitutional economic, Collective rights.

\section{JESÚS DANIEL TOVÍO FLÓREZ}

Miembro del Grupo de Invest RAFAELA SAYAS CONTRERAS

Abogada. Docente investigadora de la Universidad de Cartagena. Directora de Grupo de Investigacion Conflicto y Sociedad de la Universidad de Cartagena. Magister en Derecho de la Universidad Nacional de Colombia. Ph.D. en Sociología de la

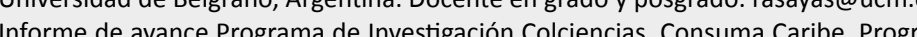

des de los consumidores en la costa Caribe colombiana. 


\section{INTRODUCCIÓN}

La expedición del nuevo Estatuto del Consumidor introduce en Colombia una perspectiva actual de las relaciones de consumo, siguiendo la tendencia mundial en torno de la vulnerabilidad de los consumidores frente a las asimetrías que produce el mercado. Asi las cosas, este trabajo aborda el desarrollo histórico y jurídico del Derecho del Consumo en Colombia. Para tales efectos se analizará el desarrollo de esta novedosa rama del Derecho en el contexto internacional, rastreando su origen en el Derecho romano, las variaciones que experimentaron las relaciones contractuales con la Revolución Industrial, hasta llegar a la sociedad de consumo a mediados de siglo XX. Posteriormente se dará cuenta de los desarrollos normativos del Derecho del Consumidor en Colombia, tomando en consideración la protección inicial que expresa el Código Civil, luego las establecidas en el Código de Comercio que introdujo algunas garantías a favor del comprador y la Ley 73 de 1981 con sus Decretos Reglamentarios, hasta la constitucionalización de los derechos de los consumidores en la Constitución de 1991, reconocidos como Derechos Colectivos, también llamados Derechos de Tercera Generación, los cuales nacen a mediados del siglo XX, producto de las transformaciones sociales acaecidas en la postguerra.

\section{METODOLOGÍA}

Se trata de una investigación jurídica, de tipo analítico, documental, de carácter cualitativo, que se desarrollará a nivel dogmático teórico, la cual busca recopilar, sistematiza y analizar el desarrollo histórico y jurídico del Derecho del Consumo en Colombia, en el contexto de su constitucionalización.

Para el desarrollo del presente trabajo nos sujetaremos a dar respuesta a la siguiente pregunta problema: ¿Cuál ha sido el de sarrollo histórico y jurídico del Derecho de Consumidor en el contexto colombiano, teniendo en cuenta la constitucionalización del mismo a partir de la Carta de 1991? Metodológicamente el trabajo está organizado de la siguiente manera: en primer lugar se desarrollará una breve introducción acerca del tema, luego se efectuará una aproximación histórica del Derecho del Consumo en el contexto internacional, para pasar a analizar la constitucionalización del Derecho del Consumo en Colombia, y por último, se plantean las conclusiones.

\section{Aproximación histórica. Contexto inter-} nacional

El Derecho del Consumo, aunque es una rama novedosa del Derecho, se relaciona con la protección contractual heredada de Derecho romano. "Desde la época de Cicerón el vendedor es responsable de los vicios que, no siendo ignorados, oculta al comprador [...] el comprador está asistido, a ese respecto, por la actio redhibitoria y por la actio quanti minoris" (Iglesias, 1953, p.263), ejercitables en los plazos de seis meses y un año.

Quiere decir ello que el Derecho romano sentó las bases de las garantías, generali- zándose la práctica de asegurar la ausencia de defectos o precisamente lo contrario, la garantía de las cualidades poseídas por las cosas sobre las que recaía el contrato, pudiendo inclusive solicitar la resolución contractual. De la misma manera se hizo extensiva dicha exigencia a los bienes inmuebles e inclusive cobijaba la obligación de declarar respecto de esclavos y animales la existencia de enfermedades o vicios ocultos. cía al comprador que resultaba afectado en su compra dos prerrogativas, la primera relacionada con los vicios ocultos que poseía la cosa, o porque se perdía la posesión sobre la misma, como consecuencia del pronunciamiento de una Sentencia Judicial, es decir, el saneamiento por vicios redhibitorios y el saneamiento por evicción.

Posteriormente, con el advenimiento del $\mathrm{Li}$ beralismo Económico y la Revolución Industrial, se introducen cambios importantes en la sociedad, los cuales serían, entre otros, reformas normativas en las relaciones contractuales, partiendo del entendido según el cua el Derecho Privado del mundo occidental se erigiría sobre los principios de autonomía de la voluntad y la libertad contractual para favorecer el intercambio económico sin ningún tipo de obstáculos. "Argumentándose que os precios justos no podían ser determinados de mejor manera que por las convenciones mismas, ya que la oferta y la demanda creaban lo justo" (Ossa, 2010, p.209).
Así las cosas, el Derecho romano le recono-

"el individualismo y el principio de no intervención del Estado aplicados a la relación de consumo dio origen a la teoría del libre mercado y el consumidor individual" (p.2).

Los extremos en una relación comercial de este período se asumían en igualdad de condiciones en un mercado libre que se regía por las leyes de la oferta y la demanda; la intervención del Estado era mínima en la esfera privada, en esta imperaba el principio de la autonomía de la voluntad y el dejar hacer, dejar pasar.

Con el transcurrir del tiempo se demostraría que esto no era del todo cierto y que el mercado no era tan libre como se pensaba; la historia puso de presente que una sociedad sin controles, dejada a la merced del libre mercado, ha de conducir a la concentración de poderes económicos y a la sustitución de la libre competencia económica por los monopolios, lo que trajo como consecuencia que las empresas -o el sector privado- ganaran y ejercieran poder político y social. En este contexto, no se estaba garantizando la libertad de competencia ni la justicia contractual, ocasionando la vulneración de los derechos de los consumidores ya que estos estaban en una situación de inferioridad en el mercado.

A principios del siglo XX, por motivo de la crisis económica de los años 30 y las dos gue rras mundiales (postguerra), empezó a surgir y reconocerse la sociedad de consumo, y el mercado empezó a experimentar cambios, pues empieza a crecer $y$ a diversificarse ante 
debido a la privación que vivieron los consumidores de los mismos, como consecuencia de los conflictos bélicos y la llamada Gran Depresión. Nace la necesidad de brindar mayor protección jurídica al consumidor.

En la naciente sociedad de consumo las relaciones contractuales sufren cambios importantes; se pasa de la contratación tradicional en donde las partes negociaban libremente las cláusulas del contrato, a una contratación en masa en donde los empresarios imponían al consumidor cláusulas y contratos prediseñados a los compradores quienes deben aceptar sin modificar dichas cláusulas, constituyéndose como la parte débil en el contrato.

En definitiva, la realidad social y económica empezaba a cambiar. La circulación masiva de bienes y servicios hicieron de la contratación una actividad cotidiana, que exigía rapidez y donde la oferta era lanzada simultáneamente a un número indeterminado de posibles contratantes. "En este contexto se tornó imposible aplicar los principios de la contratación tradicional a los contratos de consumo, sustituyéndose las conversaciones previas y las cláusulas negociadas por cláusulas predispuestas por el contratante más fuerte" (López, 2009).

En los años 60 los consumidores fueron reconocidos como grupo social definitivo, y empezó a regularse jurídicamente su estatus. Pero la idea de reconocer a los consumidores como un grupo social que merecía una protección jurídica especial, empezó a hacer eco en los Estados Unidos. A principios de siglo XX se encuentran antecedentes de asociaciones de consumidores "concretamente la primera Liga de Consumidores, creada en Nueva York en 1891, que fue el germen de las futuras asociaciones de consumidores" (Ruiz, 2010, p.69).

Pagador y Miranda (2012) sostienen que:

De hecho el arranque del movimiento de defensa de los consumidores y usuarios, movimiento consumerista, se ubica (geográfica y cronológicamente) en el mensaje que el presidente J. F. Kennedy dirigió a Congreso Norteamericano el 15 de marzo de 1962, bajo el título "Protección de los intereses de los consumidores", donde se equiparaba al consumidor con el ciudadano-elector y se aludía a los derechos de los consumidores, destacándose los derechos de seguridad, información, elección y audiencia. (p.22)

El consumerismo hace eco también en Europa, especialmente con la aparición de las cooperativas de consumo, asociaciones con formadas para hacer frente a los efectos de la Revolución Industrial, que nacen en el seno del movimiento obrero y cuyo propósito era "agrupar la capacidad de compra de sus asociados a fin de adquirir mejor posición el mercado y obtener los productos de primera necesidad a los mejores precios, defendiendo, de este modo, los legítimos intereses de sus asociados" (Ruiz, 2010).

En diferentes latitudes, y por supuesto en
América Latina, también se ha encontrado el correlato de la protección de los consumidores con normativas de diferente índole cuya efectividad varía según las políticas públicas $y$ tutela efectiva de los derechos de los consumidores en cada país. A continuación aspectos relacionados con Colombia.

\section{Derecho de los consumidores en Colombia}

En Colombia, por muchos años la única norma que brindó protección a los contratantes fue el Código Civil (Arts. 1893 a 1927), que consagra las mismas instituciones que el Derecho romano le reconocía al comprador que resultaba afectado en su compra, a saber: e saneamiento por vicios redhibitorios y el saneamiento por evicción, tal y como se planteó anteriormente.

Con la expedición del Código de Comercio en 1971, se incorporaron nuevos tipos de proección contractual, como la venta de cosa con garantía de buen funcionamiento (Art. 932), la presunción de garantía de las cosas que se acostumbran a vender de ese modo (Art. 933) y la de vicios de calidad (Art. 939).

Así las cosas, paulatinamente el derecho del consumo y de los consumidores ha venido ganando terreno a nivel mundial. De hecho, en Colombia antes de 1991 solo existían añejas figuras heredadas del derecho romano tratándose de daños sufridos por los adquirentes en los contratos de compraventa, por ejemplo el saneamiento por evicción y por vicios redhibitorios. Con la Ley 73 de 1981, se da un paso en la defensa de los consumidores estableciéndose la "Ley General del consumo", reglamentada a través del decreto 3466 de 1982, conocido como el estatuto general del consumidor, que estuvo vigente en Colombia hasta la expedición del “Nuevo Estatuto del Consumidor", promulgado a través de la Ley 1480 de 2011. (Sayas \& Martelo, 2012, p.54)

Estas normativas del Código Civil y de Comercio colombiano, no brindaban una total protección al contractual debido a que en primer lugar no se consideraban relaciones de consumo, sino relaciones contractuales normales; se exigían múltiples requisitos para su ejercicio, plazos de caducidad reducidos y acciones de reclamación judicial a través de procesos muy extensos, con lo cual materialmente el contratante vulnerado en términos de justicia se encontraba desprotegido. La Ley 73 de 1981 sería la que marcaría la intervención del Estado en la protección de los consumidores, normativa que en criterio de Ossa (2010): "Determinó la intervención del Estado en la distribución de bienes y servicios para la defensa del consumidor" (p.213)

Esta ley fue reglamentada y desarrollada por varios decretos, entre ellos, el Decreto 1320 de 1982, el Decreto 1441 de 1982, Decretos 3467 y 3468 de 1982, Decreto 2876 de 1984, Decreto 1009 de 1988, y el más trascendental de todos, el Decreto 3466 de 1982 conocido como el Estatuto del Consumidor. 
En el estatuto de 1982 no existía una dis- 3. Constitucionalización del Derecho del posición expresa sobre principios del de- Consumidor en Colombia

recho de protección al consumidor, asi

como tampoco en la Constitución de 1886 Antes de abordar el tema de la constituciose contenía alusión a la intervención esta- nalización del derecho del consumidor, es tal a favor del grupo de personas cataloga- importante precisar algunos aspectos de do como consumidores. (Giraldo, Caicedo Estado Social de Derecho para comprender \& Madriñán, 2012, p.1) Estado Social de Derecho para comprende
cómo el modelo social resignifica las relaciones de producción-consumo. Este surge A continuación podemos apreciar las normas después de la Segunda Guerra Mundial, ante relacionadas con el tema:

la necesidad de asegurar la subsistencia de

\begin{tabular}{|c|c|c|}
\hline Norma & Objeto & Aspectos relevantes \\
\hline Decreto 1441 de 1982 & \begin{tabular}{|l|} 
Por medio del cual se regula la organizacaión, el \\
reconocimiento, el control y la vigilancia de las \\
ligas y asociaciones de consumidores.
\end{tabular} & $\begin{array}{l}\text { Regula la organización, el reconocimiento y el régimen de } \\
\text { control yvigilancia de las ligas y asociaciones de consumidores. }\end{array}$ \\
\hline Decreto 3466 de 1982 & 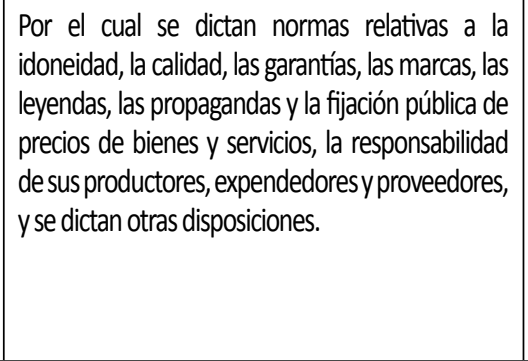 & $\begin{array}{l}\text { Se regularon aspectos como la idoneidad, la calidad, las } \\
\text { leyendas, las marcas,lapublicidaddeprecios,laresponsabilidad } \\
\text { de productores yexpendedores; de igual manera sedefinieron } \\
\text { los conceptos básicos del derecho de consumo tales como } \\
\text { consumidor, proveedor, productor, propaganda comercial, la } \\
\text { idoneidad de un producto o servicio, los registros de calidad } \\
\text { de bienes y servicios, las garantías que pueden tener los } \\
\text { productos y los procedimientos administrativos y judiciales } \\
\text { para hacer cumplir las obligaciones alli impuestas. }\end{array}$ \\
\hline Decreto 3467 de 1982 & $\begin{array}{l}\text { Se dictan unas normas relativas a las ligas y } \\
\text { asociaciones de consumidores. }\end{array}$ & $\begin{array}{l}\text { Reconoce las asociaciones distritales de consumidores y le } \\
\text { asignaala Superintendenciade Industriay Comerciolafunción } \\
\text { de control yvigilancia de las mismas. }\end{array}$ \\
\hline Decreto 3468 de 1982 & \begin{tabular}{|l|} 
Por el cual se creay y organizaz el Consejo Nacional \\
de Protección al Consumidor.
\end{tabular} & $\begin{array}{l}\text { Crea y organiza en Consejo Nacional de Protección al } \\
\text { Consumidor como organismo asesor del Gobierno Nacional, } \\
\text { entodas las materias relacionadas con lacción administrativa } \\
\text { de protección y defensa de los consumidores, adscrito al } \\
\text { Ministeriode Desarrollo Económico yseñala sus funciones. }\end{array}$ \\
\hline Decreto 2876 de 1984 & Dicta normas sobre el control de precios. & $\begin{array}{l}\text { Una vez que se haya fijado el precio y/o el margen de } \\
\text { comercialización por la entidad competente de un bien } \\
\text { o servicio sujeto a control, ningún productor, distribuidor, } \\
\text { comerciante o intermediario podrá cobrar sumas superiores } \\
\text { so pena de incurrir en las sanciones previstas en este decreto } \\
\text { sin periuicio delas contempladas en el Código Penal. }\end{array}$ \\
\hline Decreto 1009 de 1988 & \begin{tabular}{|l|l|} 
Por la cual se crean y organizan los Consejos \\
Departamentales de Protección al Consumidory \\
el Consejo Distrital de Protección al Consumidor.
\end{tabular} & $\begin{array}{l}\text { Crea los Consejos Departamentales de Protección al } \\
\text { Consumidorr como organismos asesores del Gobierno } \\
\text { Departamental y yomo delegatarios del Concejo Nacional de } \\
\text { Protección al Consumidor, en todas las materias relacionadas } \\
\text { con la acción administrativa de protección y defensa de los } \\
\text { consumidores, al Ministro de Desarrollo Económico. }\end{array}$ \\
\hline
\end{tabular}

Estado de Derecho y de las libertades y derechos del hombre; justamente este será el instrumento jurídico que utilizaría el liberalismo para enfrentar las ideas del fascismo y el socialismo marxista y para legitimar las categorías nacientes de Derecho que surgieron después de la Segunda Guerra Mundial. Se pasa al modelo social que protege y legitima una nueva generación de derechos de segunda y tercera generación, se replantea la Constitución como fuente formal de Derecho y se le da mayor importancia al papel del juez en relación con el legislador y la administración pública, derivado en gran parte de aplicación de los principios y valores constitucionales y su aplicación en las decisiones judiciales.

El Estado Constitucional y Democrático de Derecho se deriva de una mayor intervención del Estado en el ámbito político y jurídico que se manifiesta a través de la creación de mecanismos de democracia participativa de control político y jurídico en el ejercicio del poder y sobre todo, a través de la consagración de un catálogo de principios y de derechos fundamentales que inspiran toda la interpretación y el funcionamiento de la organización política. es posible afirmar que el y dejaba pasar, so pretexto de una garantia Estado Constitucional y Democrático de De- de libertad e igualdad entre oferentes y derecho tiene tres dimensiones: Una dimen- mandantes dentro de un régimen de libre sión económica, la cual se evidencia en el competencia como máxima expresión de la intervencionismo del Estado en la economía, iniciativa privada, solo favorecía a las clases como el Estado que garantiza estándares mí- dominantes y marginaba a la mayoría de los nimos de salario, alimentacion, salud, habi- miembros de la sociedad, los cuales eran los tación, educación, etc.; una dimensión políti- menos favorecidos económicamente. 
Con el surgimiento del Estado Social y Democrático de Derecho se abandona el individualismo y el principio de no intervención del estado en el campo político, económico y social; el Estado Social de Derecho pasa a tener una incidencia importante en la organización política, económica y social; "el Estado activó su función de protección y responsabilidad social hacia

mayoría de los ciudadanos". (López, 2003, p.3)

En este nuevo modelo de Estado se replantean los principios de propiedad y autonomía de la voluntad; estos principios que en la doctrina económica liberal clásica eran considerados absolutos, en el Estado Social de Derecho se relativizan. La propiedad privada y la autonomía de la voluntad ahora cumplen una función social. La concepción de contrato en las relaciones de consumo también sufre cambios en dichas relaciones, la contratación ya no se da en un plano de simetría, en donde ambas partes estaban en igualdad de condiciones y podían discutir libremente las cláusulas del contrato y este era ley entre ellas, sino que, en la sociedad de consumo la contratación es adhesiva y en masa lo que supone un plano de asimetría y es por esto que surge la necesidad de proteger al consumidor. Giraldo, Caicedo y Madriñán (2012) afirman:

Dicha revaluación de principios del derecho privado patrimonial, tiene como causa esencial el enunciado de la asimetría de las condiciones de los consumidores usuarios frente a los productores y expen- dedores, como afirmación básica del derecho de protección al consumidor, fuente de la que deriva la estructura de su normatividad. (p.2)

El reconocer esa asimetría en las relaciones de consumo, es lo que ha servido de motor para que muchos países consagren en sus constituciones los derechos, valores, principios que refuercen y garantizan la protección de los consumidores.

La Constitución ordena la existencia de un campo de protección a favor del consumidor, inspirado en el propósito de establecer su igualdad frente a los productores y distribuidores, dada la asimetría real en que se desenvuelve la persona que acude al mercado en pos de satisfacción de sus necesidades humanas. (Corte Constitucional, Sentencia C-1140 de 2000)

Es por ello que las relaciones de consumo no podían seguir rigiéndose por los códigos decimonónicos inspirados en los principios de autonomía de la voluntad y libertad contractual que no reflejaban la real evolución de las relaciones de mercado. En esa línea afirma Calle (2010):

Nuestros códigos decimonónicos se siguen rigiendo por el dogma de la autonomía de la voluntad, y de la libertad contractual, desconociendo la situación socioeconómica del consumo masivo, $y$ de la contratación en masa en donde interés del consumidor, llámese arrendatario, comprador, depositante, ya no es un interés individual o privado frente a otro interés también privado del arrendador, vendedor, etc., sino que es un interés de grupo llamado grupo llamado empresario. (p.183)

En Colombia, es apenas con la Constitución de 1991 que se le otorga un tinte constitucional al derecho del consumidor, en el contexto del régimen económico constituciona y en el ámbito de los derechos colectivos.

El artículo 334 de la Constitución Política consagra la intervención del Estado, por mandato de la ley, en la producción, distribución, utilización y consumo de los bienes, y en los servicios públicos y privados, para racionalizar la economía con el fin de conseguir el mejoramiento de la calidad de vida de sus habitantes. Ahora, esta norma, cuando sea aplicable en la política de consumo se debe hacer en concordancia con el artículo 78 de la Constitución Política, que establece la protección del consumidor como un derecho colectivo, según el cual será la ley la que regulará el contro de calidad de bienes y servicios ofrecidos y prestados a la comunidad, así como la información que debe suministrarse al público en su comercialización. (López, 2003, p.13)

En el Estado Social se constitucionaliza e sistema económico con el propósito de conservar y hacer operantes las garantías en materia económica y evitar, como acaeció en el pasado, que imperara el dogma del liberalismo clásico de que la economía tiene sus pro- pias leyes que la rigen y evitar también que el sistema dependiera de los cambios de los gobernantes de turno, los cuales producían inestabilidad económica.

Tradicionalmente en las constituciones no se consagraba el sistema económico que imperaría, lo que se hacía era plantear principios económicos que al ser interpretados podían fácilmente conducir a interpretaciones ambiguas o contradictorias, haciendo inoperante asegurar las garantías constitucionales en materia económica. Esta situación era consecuencia de la necesidad de los gobernantes para garantizar una discrecionalidad que determinará aspectos fundamentales del orden económico, basados en que la economía tiene una dinámica propia, ... Pero el sistema económico, no debe someterse a los cambios de los gobernantes, puesto que ello conduciría a la posibilidad de una inestabilidad política y económica; lo que se busca es que la Constitución defina la estructura y organización de la economía, .. de una forma amplia y flexible que permita optar entre limitadas formas de organización económica, como modificaciones alternativas de la estructura que define la Constitución, adaptando la norma a la realidad, sin que ello implique un orden socioeconómico distinto que pueda resultar contrario a la misma. (López, 2001, p.24)

La Constitución de 1991 no consagró de manera expresa el régimen económico de Colombia, en esta materia la Constitución colombiana es ambigua y abstracta; lo anterior 
no quiere decir que en Colombia el sistema mía de mercado se induce de varias normas económico está sujeto a los vaivenes de la constitucionales que hacen mención al miseconomía o al de los gobiernos de turno. mo y que reconocen las libertades económiPara determinar el sistema económico en cas, conformadas por la libertad de empresa Colombia es necesario integrar los princi- y la libre competencia consignadas en el arpios, valores y derechos que ha consagrado tículo 333 de la Constitución, libertades que la Constitución, debido a que este está implí- solo tienen razón de ser en una economía de cito en los mismos, sobre todo los que rigen mercado. A este respecto Angarita (como se la actividad económica llevada a cabo por el citó en López, 2001) afirma:

Estado, para de esta forma poder deducir dicho sistema. "Realmente, más que Constituciones indiferentes, neutras o beligerantes, hay Constituciones que consagran expresa y directamente un sistema económico y Constituciones en las que el sistema subyace bajo los principios generales y está implícito en los derechos individuales y colectivos" (Rojo, como se citó en López, 2003, p.5).

Es importante tener en cuenta que la Constitución de 1991 erigió a Colombia como un Estado Social de Derecho, el cual, además de ser el modelo de Estado que la Constitución implementa en Colombia, también es un principio que irradia todo el orden político, jurídico, social y económico; y es a través de ese principio fundamental que se debe garantizar y asegurar la justicia y un orden económico y social justo, como valores o fines de dicho Estado. La realización de esos fines debe realizarse en el marco de un régimen económico intervencionista como lo establece el artículo 334 de la Constitución Nacional. Ahora, el concepto de mercado no desaparece con la Constitución del 91; de hecho la estructura del régimen económico es el de economía de mercado, pero interven por el Estado Social. La estructura de econo-
Las libertades económicas, constituidas por la libertad de empresa y la libre comla Constitución Política de 1991, no pueden realizarse en otro marco que no sea la economía de mercado. La libertad económica constituye la base de la libertad política y el instrumento a través del cua la persona se procura su propio bienestar en un mercado. (p.26)

De esta manera se infiere que en la Constitución del 91 las libertades económicas no son absolutas, sino que se encuentran limitadas por la intervención y dirección del Esen la economía, lo que permite deducir que el sistema económico de Colombia es un sistema mixto en el que confluyen aspectos de una economía de mercado y de una economía planificada o central, lo que se podrí denominar como una economía social de mercado en donde las libertades económicas, propias del mercado, están limitadas por los principios y valores constitucionales reguladas por la intervención del Estado.

El sistema económico va intrínsecamente ligado con los derechos de los consumidopetencia consagradas en el artículo 333 de res y su protección; el Estado Social tiene un interés en la protección de los consumidores, y ese interés deviene como la afirma Calle (2010) que: "En los sistemas económicos organizados alrededor del mercado, el consumo constituye el último eslabón en el proceso de circulación e intercambio de las mercancías" (p.182)

El consumidor es el último eslabón en el ciclo productivo, es el destinatario final de los bienes y servicios con los cuales busca satisfacer sus necesidades humanas. A raíz de los cambios económicos y sociales ocurridos en la segunda mitad del siglo $\mathrm{XX}$, se puso de presente la inferioridad en que se encuentra el consumidor en un mercado dominado por la ley económica de la oferta y la demanda y es por ello que el Estado debe implementar una política de consumo que garantice los derechos de los consumidores en el marco de una economía de mercado y de libre competencia económica.

La política del consumo, debe igualmente interrelacionarse directamente con lo que se ha dado en llamar constitución económica o sea con el sistema económico consagrado, el cual corresponde al de la ecoomía de mercado, pues en la ley fundamental encontramos un conjunto de preceptos que encaminan la intervención de Estado hacia una determinada dirección funciones. En este orden de ideas se piensa en el artículo 334, que consagra la libre competencia económica, pero establece cortapisas, pues garantiza que el Estado controlará cualquier abuso de personas o empresas que hagan de su posición dominante en el mercado, a su vez delimitará el alcance de la libertad económica cuando así lo exijan el interés social, el ambiente y el patrimonio cultural de la Nación. (Calle, 2010, p.184)

Es pues, ante esa condición de inferioridad en que se encuentra el consumidor en el mercado, que se justifica la intervención del Estado en las relaciones de consumo a través de la creación y promoción de mecanismos e instrumentos que regulen la contratación en masa o de consumo y los contratos de adhesión. Esa protección estatal se materializa cuando el Estado es llamado a restablecer el equilibrio contractual en los contratos de consumo, garantizando que el consentimiento expresado corresponda con una elección libre e informada, dejando sin eficacia jurídica todo pacto o cláusula que lesione los intereses del consumidor y estableciendo en caso de que corresponda el ejercicio de las garantías legales y las responsabilidades por daños a cargo de fabricantes y distribuidores.

\section{CONCLUSIONES}

El desarrollo histórico y jurídico del Derecho del Consumo ha desembocado en que esta rama del Derecho, hoy día tenga la importancia y relevancia jurídica que se merece, pues en un mundo de economía globalizada, como en el que se desenvuelven hoy día las relaciones comerciales, no se pueden seguir regulando las relaciones de consumo con los viejos y anacrónicos códigos civiles decimonónicos inspirados por el dogma de la 
autonomía de la voluntad y la libertad con- de la Constitución Nacional, que establece tractual, la cual supone un plano de simetría los derechos de los consumidores como decontractual; ni con la legislación comercial, recho colectivo.

por cuanto esta última solo protege los intereses de los fabricantes y distribuidores, siendo ajeno al último eslabón de la cadena productiva: los consumidores. Dichas relaciones de consumo demandan una protección constitucional y legal que proteja los intereses de los consumidores como parte débil en las relaciones de consumo.

El desarrollo histórico y jurídico de esta rama del Derecho ha culminado, al igual que las diferentes ramas del Derecho, en el fenómeno jurídico de la constitucionalización del Derecho, lo que implica la consagración en las constituciones de postguerra, de los derechos de los consumidores y su reconocimiento como un grupo social que merece una especial protección jurídica en las relaciones de consumo que se dan en el marco de una economía social de mercado.

La constitucionalización de los derechos de los consumidores en Colombia, implica dos ámbitos importantes en el marco de la Constitución de 1991; en el primero, el régimen económico, y el segundo, los derechos colectivos. El Estado por mandato del Art. 334 de la Constitución Nacional debe intervenir en el ciclo productivo, para así lograr un orden económico incluyente en el que gocen de especial protección los sectores que se encuentren en situación de inferioridad o desventaja, como lo son los consumidores, lo que debe estar en relación con el Art. 78

\section{REFERENCIAS BIBLIOGRÁFICAS}

Angarita, C. (1996). "La libertad económica en la jurisprudencia de la Corte Constitucional: aproximación fugaz". Constitución Económica colombiana. Bogotá: El Navegante Editores.

Calle, R. (2010). Derechos colectivos y del ambiente. Recuperado de http://www.udea. edu.co/portal/page/portal/bibliotecaSedesDependencias/unidadesAcademicas/FacultadDerechoCienciasPoliticas/PublicacionesMedios/EstudiosDerecho/SegundaEpoca/ Tab/Vol\%20XLIX\%20Rev\%20117-118\%20 parte\%2010.pdf

Corte Constitucional colombiana. Sentencia C-1140 de 2000.

Giraldo, Caycedo \& Madriñán (2012). Co mentarios al nuevo Estatuto del Consumidor.

Iglesias, J. (1953). Derecho romano. Instituciones de Derecho Privado, II. Barcelona: Ariel. Colombia: Editorial Legis.

López, C. (2001). Constitución económica mercado y derechos del consumidor. En: Revista Contexto, 24-30.

López, C. (2003). Derechos del consumidor: Consagración constitucional en Latinoaméri-

ca. Revista Mercatoria, 2(2), 1-42.
López, E. (2009). La defensa de los derechos Rojo, A. (1983). Actividad económica pública del consumidor desde una perspectiva inter- y actividad económica privada en la Constinacional. En: Revista Amicus Curiae. México: $\quad$ tución española. Revista de Derecho MercanUniversidad Autónoma de México. til, 169-170.

Miranda, L. \& Pagador, J. (2012). Derecho Ruiz, J. (2010). Las asociaciones de consumi(privado) de los consumidores. España: Edi- dores. España: Tirant lo Blanch. torial Marcial Pons.

Sayas y Martelo (2012). Aspectos regulatoOssa, D. (2010). Protección, garantía y efica- rios del consumo en Colombia. Autoridades cia de los Derechos del Consumidor en Co- y responsabilidades. En Saber, ciencia y liberlombia. Revista Facultad de Derecho y cien- tad, 7(2), 53-61.

cias políticas, 40(112), 203-239. 